\title{
STRUCTURAL OPTIMISATION AND SUSTAINABLE DESIGN
}

\author{
W.P. DE WILDE, T. VANDENBERGH \& W. DEBACKER \\ Department of Mechanics of Materials and Constructions (MeMC), Vrije Universiteit Brussel, Belgium.
}

\begin{abstract}
The theory of morphological indicators $(M I)$ provides user-friendly tools guiding the structural designer towards low volume consuming solutions during the exploration and comparison of different structural types. Since a first doctoral thesis published in 1999, a decade of research has refined MI into a benchmarked structural optimisation method for conceptual design. This article surveys the milestones that lead to today's method and contains the published references that contributed to the major evolutions of $M I$. The article also refers to the work of other researchers in structural and architectural engineering, this time in the quest of optimisation of structures through a more sustainable design, offering the possibility of re-use and recombination of structural components. This technique, called 4D design methodology, was based on a research proposal by Hendrickx and Van Walleghem, which was further developed at Vrije Universiteit Brussel.

Keywords: 4D Design methodology, conceptual design, fully stressed design, morphological indicators, structural optimisation, sustainable design, volume minimisation.
\end{abstract}

\section{INTRODUCTION}

Designing a new structure is a complex process. A systematic approach permits a clear and logical record of the development of a new design. Generally, it begins with a need and ends with drawings to enable the design to be built. The intervening stages should be of successively precision, of gradual crystallisation or hardening, as described by French [5]. The early stages are characterised by a great fluidity and major decisions can be made or modified. This stage is called conceptual design. At conceptual design stage, there is plenty of opportunity for making changes and suggesting improvements. Once detail design commences, this opportunity is reduced and corresponding cost for making changes increases exponentially as more resources are committed. Nevertheless, today's peak in design changes occurs much later and is obviously very costly to implement. The aim is to move this peak to a more profitable earlier stage. Providing a good conceptual design - or a good starting point - avoids late, detailed and costly optimisation of a bad initial design. Therefore, it is of prime importance to provide quickly good estimations related to different concepts without limiting the ability to freely explore the design space. It is based on this main idea of free exploration that morphological indicators (MI) are developed, offering - without need for detailed calculation - good approximations of different structural performances (material consumption, displacement, vibration response, etc.) in comparison between different structural concepts.

The quest for lesser material consumption in advanced steel design brings one to thinwalled profiles, hereby achieving stiffness requirements through the form of the sections, open or closed. The contribution of Belgian researchers and scientific centres should be underlined.

The efficiency of a structure can be evaluated from different perspectives and depends on many variables. The selection of a specific criterion is based on a philosophical position. Economical, social, cultural, political, legal, ecological, esthetical, etc. are listed by Samyn [6] as possible criteria in the assessment of structural performance. Usually, the total cost of 
a design is used for an objective comparative study of different concepts. The volume or mass of a structure represents only a part of its overall cost. Fabrication and transportation of its members as well as erection are major parts of the total bill. These costs vary greatly as a result of time, technology, legislation, location, etc. making an objective (time and place independent) study and quantification of 'the' cost very difficult. Volume is a characteristic that only depends on the structure itself, which makes it suitable for universal theoretical reflection. Volume can be considered as a price without location and age. It is important to mention here that the following simulation tools were introduced, as they were needed for objective assessment of competing solutions: life-cycle cost (LCC) and life-cycle analysis (LCA).

And although volume does not represent the entire cost in LCA [4], it should be emphasised that a low material consumption not only limits the energetic impact of the structure itself but also decreases the cost of procurement, transportation and construction related to it. Furthermore, it implies lower emissions and waste in the post use stage. Hence, a second important reason for volume as efficiency criterion results from an ecological point of view. Finally, the recent evolution of material and fuel prices, compared to the relatively slower rise in salaries, tends to bring the minimisation of economical cost and volume together.

The theory of MI provides user-friendly tools guiding the structural designer towards low volume consuming solutions during the exploration and comparison of different structural types, at conceptual design stage.

\section{HISTORICAL BACKGROUND}

The development of $M I$ has an important historical background. A brief overview of the milestones which lead to today's theory is necessary to provide more insight and to better situate $M I$ in the continuously evolving world of structural optimisation.

Maxwell [7] created a major turning point in the optimisation of pin-jointed frameworks subjected to a single applied loading condition by proving

$$
\sum_{i=1}^{m} l_{i}^{t} N_{i}^{t}+\sum_{i=m+1}^{n} l_{i}^{c} N_{i}^{c}=\text { constant }
$$

or the sum of the product of the bar length by its normal force [positive for tension (with superscript $t$ ), negative for compression (with superscript $\mathrm{c}$ )] over all bars is a constant which only depends on the applied load and the boundary conditions. Michell [8] published a method based on Maxwell's contribution in which optimal lay-outs for minimum-weight trusses under a single load case are presented. Based on Lévy's theorem, the resulting structures are statically determined (Indeed, Lévy [9] was able to show that a lattice under a constant load case must be statically determined in order to be optimal.). The planar fully stressed solutions offered by Michell are very often impractical but they do provide a basis for comparison against which practical designs may be evaluated. In perspective of the definition of MI, it is interesting to mention one equation from his work: ' ... considering a number of different frames in equilibrium under the same set of external forces, in that one of the frames for which the volume is least the following sum is least...:'

$$
\sum_{i=1}^{\text {bars }} l_{i}\left|N_{i}\right|
$$


or the frame of minimal volume has the minimal sum of the product of the bar length with its axial force, over all bars. In the next section, the concept of indicator of volume is introduced. The analogy proves the power of the indicator of volume as an optimisation tool.

In the context of MI, a retrospective should mention the work of Zalewski [10] and Zalewski and Kus [11, 12], which compares the self-weight and displacements of various typologies of trusses with respect to the flow of forces and the flux of the stresses in beams and plates. Considering that the structure can be framed within a rectangular window with dimensions $\mathrm{L}$ and $\mathrm{H}$ (with $\mathrm{L} \geq \mathrm{H}$ ), the link between the geometrical slenderness $L / H$ and both volume and displacement of trusses is hereby demonstrated for the first time. Ripoll [13, 14] shows the link between the volume of arches and trusses and the geometrical slenderness $L / H$. It is important to mention here that neither Zalewski nor Ripoll considered instability in their work. Their contribution can be considered as the first expression of MI (more specifically the indicator of volume), since for statically determined arches and trusses the volume $\mathrm{V}$ of the fully stressed structure is expressed as

$$
V=f\left(\frac{L}{H}\right) \cdot \frac{F L}{\sigma}
$$

in which $\mathrm{F}$ represents the total action and the allowable stress.

\section{MORPHOLOGICAL INDICATORS}

Based on above-mentioned works, Samyn started in 1997 by a methodical study of the volume and displacement of structures and expressed in his doctoral thesis [1] the link with the slenderness $\mathrm{L} / \mathrm{H}$, if buckling of the compressed elements is ignored. The results are synthesised in what is called the theory of morphological indicators. MI are defined as 'dimensionless numbers that represent a geometrical property or a physical performance of a structure' [15].

Only considering criteria on resistance, a clear hierarchy among the different structural archetypes is established with the indicator of volume $W$ :

$$
W=\frac{\sigma V}{F L}
$$

It is the volume $V$ of an isomorphic structure with span $L$, with at least one section dimensioned at its allowable stress $\sigma$, and subject to a system of loads with resultant $F$. This indicator allows the comparison of the volume of material used for different structural systems.

The displacement indicator $\Delta$ compares the corresponding maximal displacement of different structural systems:

$$
\Delta=\frac{E \delta}{\sigma L}
$$

It is the maximum displacement $d$ of an isomorphic structure with span $L$ in a material with Young's modulus $E$, with at least one section dimensioned at its allowable stress $s$, and subject to a system of loads with resultant $F$.

The analytical expressions of $W$ and $D$ have been established by Samyn $[1,6]$ for some structural typologies: trusses, beams, arches, cables, cable-stayed structures, masts and frames subjected to a limited number of (simple) load cases and supports. Samyn [1] and 
Latteur [16] and Latteur et al. [17-19] described the indicator of volume of axisymmetric domes and spatial trusses, but no further research is based on their results up to now.

For statically determined planar structures, $W$ and $\mathrm{D}$ are only functions of the geometrical slenderness $L / H$ or the length divided by the height of the smallest window that frames the structure. The calculations implicitly assume fully stressed design as being the optimal sizing. The work of Lévy, mentioned above [9], proves the validity of this hypothesis for statically determined structures. Instabilities, self weight and second-order effects are neglected. Efficiency curves depicting the geometrical slenderness with respect to the minimum volume of material can be established. These curves allow the comparison between different structural typologies and topologies with a reduced number of variables, as illustrated in Fig. 1. The corresponding maximal static displacement of these fully stressed structures can be found in Samyn [1, 6]. An example is shown in Fig. 2.

The simplicity of the method makes it a powerful and user-friendly tool to guide the structural designer during the first preliminary sketches of the design process. But this simplicity implies a number of strict working hypotheses [20]:

- The structure is loaded by one dominant load case.

- The structure is statically determined and supported by a hinge on one side and a roller on the other.

- The structure is built of a homogeneous linear elastic material.

- The structure is in a state of fully stressed design or every section is dimensioned at its allowable stress level.

- The slenderness of the structure and its components are supposed to avoid instabilities (e.g. buckling of compressed elements).

- The volume of the connections is neglected.

- All the internal connections in the truss systems are assumed to be perfect hinges (no bending moments are transmitted).

- The local effect of the self-weight is ignored.

- Fatigue and dynamic phenomena are not taken into account.

To enhance the accuracy of the method, a whole number of additional variables or indicators can be developed. But this would harm the ease of use of the method. In many practical cases, it is allowed and even profitable to simplify the design problem. But a good conceptual design should yield a solution that will not (or only slightly) change its relative superiority to other solutions when more detailed design calculations are performed. Hence, it is very important to assess the possible impact or necessity of detailed calculations such as (global) buckling, dynamics, weight of connections, second-order effects against others. If the context of the situation allows the use of the indicator of volume in its simplest form, a larger solution space can be explored.

It is the difficult equilibrium exercise between a user-friendly, simple method and its accuracy that forms the main problem statement of $M I$.

The very strict working assumptions, introduced by Samyn and others [20], reduce the practical applicability field drastically. Some of these limitations are tackled by Latteur in [16]. His main contribution handles explicitly buckling in the compressed elements by introducing an additional parameter called the buckling indicator

$$
\Psi=\frac{\mu \sigma L}{\sqrt{q E F}}
$$




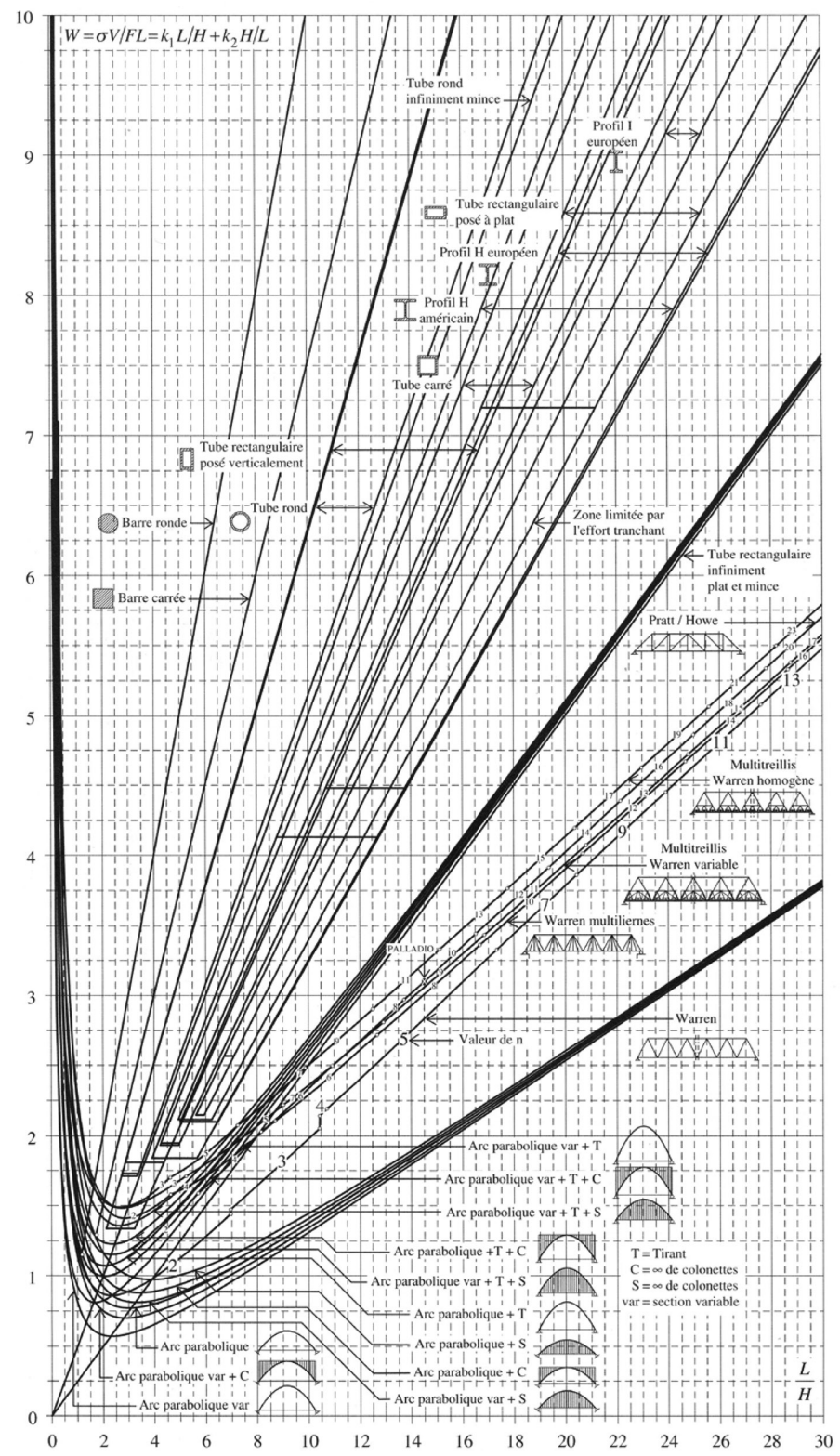

Figure 1: Volume indicator $W$ of classical structural systems only considering resistance, by Samyn [6], $n$ is the number of triangular cells (for the shown Warren beam $n=6$ ).

This factor gives an indication for the impact of the buckling tendency of the compression elements on the total volume, in a structure with span $L$, composed of bars with a form factor $q$ in a material with Young's modulus $E$, with at least one section dimensioned on its allowable stress $\sigma$, subjected to a system of loads with total resultant $F . \mu$ is the proportion of the buckling length of the compression bars over their geometrical length (which depends on the 


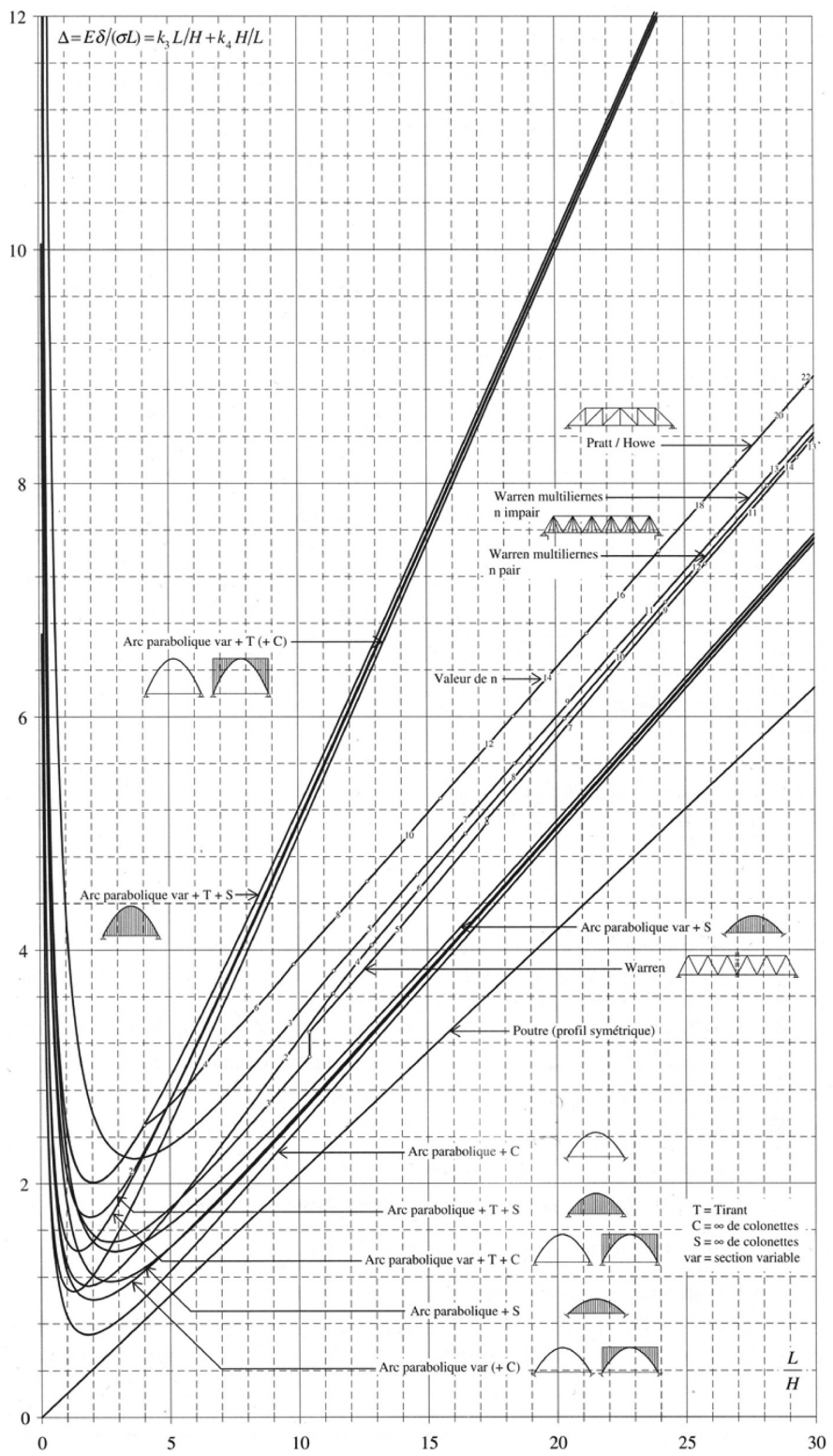

Figure 2: Displacement indicator D of classical structural systems only considering resistance, by Samyn [6].

connection type, e.g. for pinned trusses, NBN ENV1993-1 [21] allows $\mu=0.9$ ). The form factor $q$ expresses the distribution of material with respect to the centre of gravity of the section. It is defined as

$$
q=\frac{I}{\Omega^{2}}
$$


where $I$ is the second moment of inertia and $\Omega$ the section area. Another form factor $Z$, used in the expressions for beam bending, is defined for rectangular tubes with depth $h$ as

$$
Z=\frac{\Omega h^{2}}{16 I}
$$

Both factors only depend on the thickness to height ratio, $m$, of the profile. For compression, double axis symmetric profiles are used to avoid the presence of a weak buckling axis.

To reduce the buckling sensitivity of members one can see from eqn (6) that the form factor $q$ should be as high as possible. Today's available profiles have a minimal thickness to height ratio $m$ of $2 \%$. Moreover, a lower bound is required to avoid local buckling in compressed parts of the profile. Based on the Eurocodes for steel construction NBN ENV1993-1 [21], $m$ should exceed $2 \%$ for circular tubes and $3 \%$ for square tubes, which corresponds, respectively, to an upper limit for $q$ of 1.95 and 1.35 . Hence, by considering these realistic values for the form factor not only buckling of compressed members can be avoided but also local buckling in compressed zones of a profile. Note that in practical problems the designer could be limited by the available catalogue of sections, which results in a discrete and limited number of form factors and profile dimensions. Vanpee [22] published a study in which he proves that the volume increase due to the limited number of today's commercially available profiles is negligible.

The consideration of buckling modifies the element sizing, increasing the precision of the optimisation process at the cost of one extra parameter $(\Psi)$. It enables the evaluation of the extra necessary volume of material to avoid buckling. Moreover, it affects the optimal solution. For example: the higher the value of the buckling indicator, the higher the optimal slenderness and number of panels for trusses, in order to reduce the buckling length of the compressed members. The definition of the indicator of buckling clearly demonstrates that the buckling sensitivity depends on the span-load ratio $(L / \sqrt{F})$. This quantity had already been defined as the structural index by Shanley [23], in the context of aeronautical engineering. This index thus clearly shows that, although MI are dimensionless, they also in fact depend on (geometrical and load) scale effects.

The consequence on the optimal structural shape and topology can be predicted with the design graphics drawn by Latteur [16]. These design graphics depict the optimal morphology and corresponding slenderness as a function of the buckling indicator. Moreover, they demonstrate that the influence of buckling can increase the necessary volume by much more than the $25 \%$ (which was a value initially stated by Samyn [6]).

Latteur [16] tackled a second important problem by including the self-weight through the indicator of self-weight

$$
\Phi=\frac{g \rho L}{\sigma}
$$

with $g$ as the gravitational constant $\left(9.81 \mathrm{~m} / \mathrm{s}^{2}\right)$ and $\rho$ as the material's specific mass. Its value gives an indication for the fraction of the allowable stress necessary to carry the structure's self-weight. From eqn (9), it is clear that the self-weight depends on the total span of the structure. In other words, the scale of the problem is included by considering self-weight. The ratio $\sigma / g \rho$ is also known as the material breaking length (see [24]) or the length of a wire of material which, hanging freely under gravity, would just break at the top (for steel 'break' should be replaced by 'yield'). Hence, the concept of indicator of self-weight can also be used do determine the limit span of structures. 
In his doctoral thesis, Latteur [16] also proves that the indicator of volume considering resistance, buckling and self-weight only depends on the slenderness $\mathrm{L} / \mathrm{H}$, for a given topology. Worth mentioning is that the consideration of self-weight enables a more precise estimation of the necessary volume of material, but it does not change the hierarchy among the different structural topologies. The values are just rescaled, and additionally the lightest solution remains the lightest. Later Latteur developed a method to consider the bending moments in the elements due to bending rigidities in imperfectly pinned connections or due to friction. Using the indicator of rotation, the indicator of parasitic constraints and the delta-volume indicator, one can evaluate the additional volume necessary to resist these bending moments for trusses and arches [18, 19].

The work of Latteur [16] and of Latteur et al. [17, 19] clearly indicates that the influence of buckling on the volume of material can be significant, even when the best available solution is used. To further lower the volume of the compressed elements, Van Steirteghem [15] and Vanpee [22] proposed a significant reduction in the buckling length of compression members. Van Steirteghem's work [15] offers a detailed analysis of stayed compression members (see Fig. 3). Considering different cross arm geometries and connections, pretension, buckling modes and imperfections, he developed a design procedure leading to an optimal or lightest compression element.

Though Samyn [6] briefly mentions vibration problems in his book, Van Steirteghem [15] focuses for the first time on dynamic effects when designing constructions with $M I$, realising that an optimum obtained by minimising the volume only considering strength, often results in solutions with problematic dynamic behaviour. To predict the risk of resonance, Van Steirteghem [15] develops a tool allowing the estimation of the first natural frequency of a structure. An 'indicator of first natural frequency' is hereby defined as

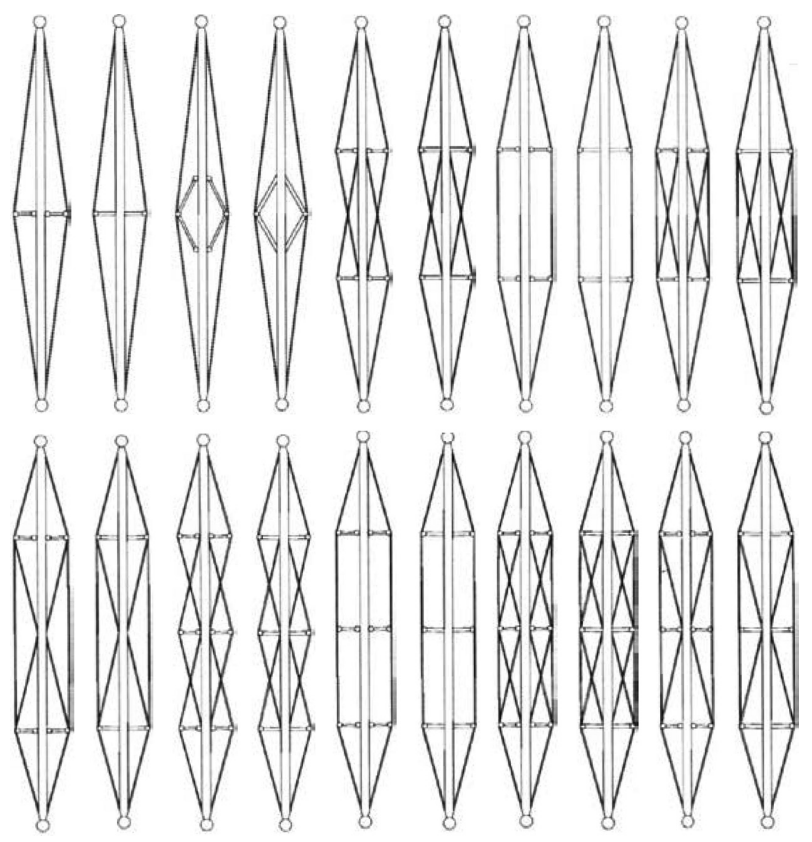

Figure 3: Typologies of stayed compression members studied by Van Steirteghem [15]. 


$$
\Theta=2 \pi f_{1} \sqrt{\frac{z^{*} L \sigma}{g E}}
$$

where $f_{l}$ is the first eigenfrequency of a structure with span $L$, with at least one section dimensioned at its allowable stress $\sigma$, built from a material with Young's modulus $E$ and for which the ratio of the co-vibrating load to the total load $z^{*}$ is 1 in Serviceabiltiy Limit State ( $g$ is the gravitational acceleration $9.81 \mathrm{~m} / \mathrm{s}^{2}$ ).

Based on a single degree-of-freedom (SDOF) model of a statically determined beam and the approximation of a similar shape between static displacement and first global vibration mode, a first prediction of this indicator has been formulated in Van Steirteghem [15] with the indicator of static displacement

$$
\Theta=\frac{c_{c o r}}{\sqrt{\Delta}}
$$

The correction coefficient $c_{\text {cor }}$ is necessary to compensate the approximation implied by a SDOF model. For statically determined trusses and beams values are 1.10 and 1.13 , respectively. Hence, the indicator of first natural frequency is depending on the same variables as the indicator of displacement: the buckling indicator and the slenderness, for a given topology. This information allows predicting the first eigenfrequency of statically determined trusses and beams at conceptual design stage. Moreover, it allows modifying the initial design to another fully stressed solution to avoid resonance. The possibilities offered by a global stress level reduction are also discussed. It is clear that reducing the allowed stress level from $\sigma$ to $\beta \sigma(\beta<1)$ asks for more material and therefore increase the structural stiffness. Considering eqn (10), the corresponding augmentation of the natural frequency can be predicted. But lowering the allowable stress level results in higher necessary structural mass; a consequence that should be avoided in the frame of volume optimisation.

\section{BENCHMARKING THE METHOD BY ADDITIONAL DESIGN CONSTRAINTS}

A structure does not only have to meet resistance requirements, but should as well not violate constraints concerning functionality, comfort and appearance. In some cases, these constraints are more restrictive than strength-based ones and can determine the structural layout. As presented in Section 3, MI are design tools which are essentially based on fully stressed design, clearly indicating that strength (with regard to element buckling) is considered as most important design criterion.

The indicator of displacement allows predicting the maximal static displacement of the structure and can be used to verify if the strength optimised structure does not violate constraints on displacement. When displacements are unacceptable, Vandenbergh et al. [26, 27] proved that the theory of MI, with sizing based on a fully stressed design, does not necessarily lead to optimal (i.e. lightest) solutions. Hence, it is essential to provide information about the most restrictive design criterion during the first design steps to avoid important structural modifications due to the use of an inappropriate optimisation methodology. In this perspective, additional design criteria were included through the development of new MI.

A first extension concerned instabilities. The introduction of the indicator of buckling $\Psi$ and upper limits on the form factor $q$ enables to avoid local buckling effects, though global planar instabilities of trusses (and truss arches) cannot be predicted with these indicators. 
Vandenbergh et al. [28] and Vantomme [29] presented therefore the 'indicator of global planar stability'

$$
\Lambda_{c r}=\frac{F_{c r} \sigma}{F E}
$$

It is the lowest critical load $F_{c r}$ at which the structure undergoes a planar instability, when it is dimensioned for a unit external load $F$, with an allowable unit stress level $\sigma$ and from a material with unit Young modulus $E$. The global planar stability of a structure is guaranteed when the applied external load is lower than the critical global buckling load, which can be translated as a lower limit on the indicator of global planar stability

Structure globally stable if $F_{c r}>F \Leftrightarrow \Lambda_{c r}=\frac{F_{c r}}{F} \frac{\sigma}{E}>\frac{\sigma}{E}$

With this new tool, the stability of a trusses (and truss arches) can directly be assessed. This indicator depends on the same variables as the indicator of volume. Based on this knowledge, Vandenbergh et al. [28] and Vantomme [29] studied the strength and stability of three-hinged parabolic truss arches and developed design graphics showing their indicator of volume and global planar stability as a function of the global slenderness. With these graphics the structural designer can find the morphology (number of panels, slenderness, etc.) of the lightest solution, assess the corresponding volume and predict its global planar stability (an example is given in Fig. 4). Vandenbergh and De Wilde [30] computed $\Lambda_{c r}$ for a truss column and confirmed the fact that strength optimised solution, with sizing based on fully stressed design, does not guarantee the lightest solution when global stability is also considered.

The trend towards the use of more slender and larger structures requires today's structural engineers also to design dynamically responsive structures. The ability to identify dynamically sensitive structures has therefore become a necessary part of a structural engineer's skills. The design of dynamically responsive structures for safety, meeting performance requirements for dynamic vibration, is a relatively difficult subject [31]. Without undermining the importance of a complex dynamical study of a structure during its detailed analysis phase, there is a need to be able to predict potential problematic dynamic behaviour in the conceptual phase of the project. The sooner a problem is identified, the easier the project can be adapted.

Nowadays, there appears to be two main concepts for satisfying vibration serviceability: the first requires the calculation of the dynamic response and checking if it is within the acceptable limits (usually expressed in terms of maximal peak acceleration). The second approach is based on the request to avoid structural natural frequencies within the excitation range since this can potentially lead to resonance. Vandenbergh and De Wilde [32,33] and Vandenbergh et al. [34] published different papers, presenting a non-exhaustive overview of limit values imposed on eigenfrequencies and accelerations, based on Standard 5400 [35], Bro2004 [36] and Zivanovic et al. [37].

In both design approaches, the concept of eigenfrequency plays a fundamental role. The results obtained by Van Steirteghem (see eqns (10) and (11)) [15] are based on a SDOF model and assumes a vibration mode with shape similar to the static displacement. The articles of Vandenbergh and De Wilde [32] and Vandenbergh et al. [38] and the master theses of Lefevre [39] and Spranghers [40], confirmed these equations for beams, refined them for trusses and 


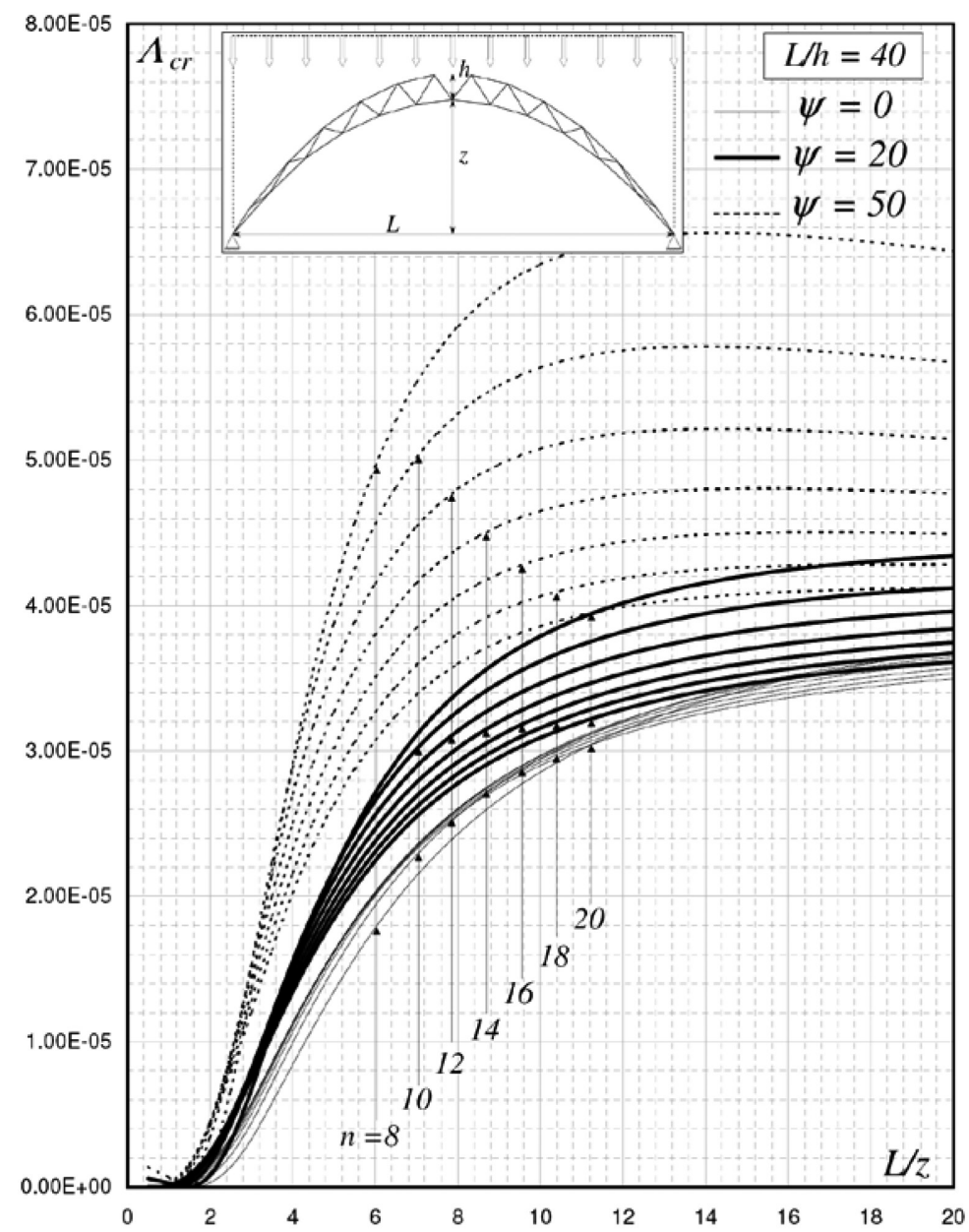

Figure 4: Indicator of global planar stability of three-hinged parabolic truss arches [40].

corrected them for arches. For trusses, the correction factor $c_{c o r}$ seems not to be constant but depends on the slenderness, the number of panels and the buckling indicator. Design graphics depicting this factor for different design parameters are given in Lefevre [39], allowing a more accurate prediction of the fundamental eigenfrequency of Warren, Pratt and Howe trusses. An example is given in Fig. 5 for a Warren truss. For arches, eqns (10) and (11) yield totally wrong estimates of their first natural eigenfrequency. But their value can be predicted as a function of their slenderness by means of only two design graphics [40, 41]: a first one for buckling insensitive arches $(\Psi=0)$ and second for buckling sensitive ones $(\Psi>0)$. Additionally, the resistance and eigenfrequency of cable-stayed beams have been analysed by Vandenbergh [42] and was further refined by Vandenbergh [43]. The possibilities offered by pretension in terms of volume reduction and eigenfrequency tuning are extensively discussed in these works, opening new perspectives for further research on the effect of pretension on the dynamic response of structures.

Besides frequency limits, design codes can also impose maximal acceleration levels. The latter type of constraint often reflects better what is perceived by people in reality. 'Design 


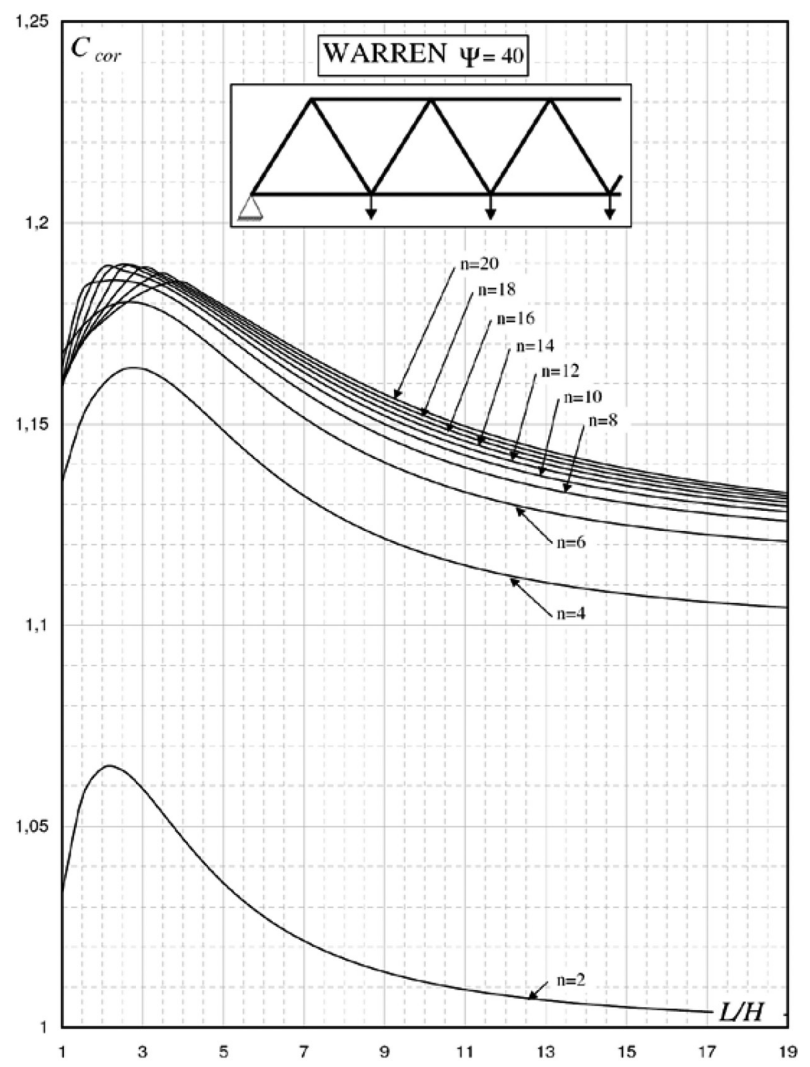

Figure 5: Correction factor on indicator of first natural frequency for Warren trusses [39].

rules which are expressed in terms of minimum natural frequencies are a means to an end, not the end itself, and these rules can be broken in some circumstances. For example, floor structures with natural frequencies below $3 \mathrm{~Hz}$ or whatever the rule specifies are possible provided they have sufficient mass and/or damping to control the response to acceptable levels.' (M. Willford, Director of Arup Advanced Technology Group, in the Arup vibration seminar [44]).

Therefore, the authors focussed on the possibility of developing tools for the prediction of peak accelerations. Vandenbergh et al. [34] extended the method of Van Steirteghem [15], based on the vibration response of a SDOF-system under harmonic excitation. Additionally, they derived the equations describing the characteristics (i.e. damping, stiffness and mass) of a Tuned Mass Damper that minimises the structural accelerations and computed the associated attainable acceleration reductions. Though this method offers a very user-friendly tool, it can result in a significant overestimation of the peak accelerations since it is based on fully developed resonance. To achieve this stage (called regime or steady-state resonance vibration), the excitation needs to be maintained during several vibration cycles (called transient stage), which is not necessarily possible due to the limited span of the structure. Especially for lightweight footbridges, the overestimation can lead to wrong design conclusions. Moreover, the accuracy of representing pedestrians by a perfect stationary cosine function is questionable. Recent research has handled these shortcomings by implementing 


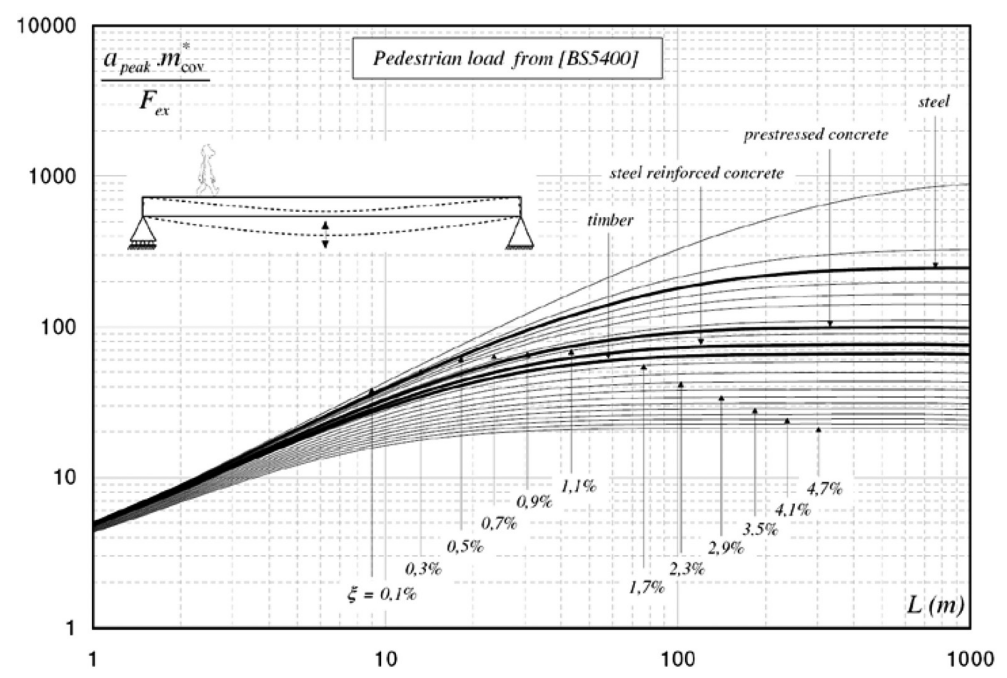

Figure 6: Peak accelerations of statically determined beams under the single pedestrian load model from [BS5400]. $\left(F_{e x}\right.$ : amplitude of excitation load, $m_{\mathrm{cov}}^{*}$ : covibrating mass in serviceability limit state) [2].

pedestrian's load models on beams, trusses and arches. The results are published in two master theses $[39,40]$ and two proceeding papers [32, 33] and provide design graphics enabling the prediction of peak accelerations $a_{\text {peak }}$, under two single pedestrian load models (defined in British Standard 5400 [35] and Bro2004 [36]) and one group load model, presented by the Association Française de Génie Civil [45]. An example is given in Fig. 6, depicting the dimensionless peak acceleration of a beam under the single pedestrian load defined in British Standard 5400 [35], as a function of the span $L$ and for different damping ratio's $x$.

\section{DESIGN FOR SUSTAINABILITY}

Most of the above-mentioned techniques were used to design architectural constructions, which often combine large spans and lightweight characteristics. The archetypes for these constructions are the footbridges of Santiago Calatrava, to be sighted all over the world and referenced in various books, e.g. Jodidio [46].

There are, however, less prestigious constructions for which criteria of both durability and sustainability are of paramount importance. A group of researchers at Vrije Universiteit Brussel, Brussels, was headed by De Wilde and Hendrickx (starting 2004) and developed a so-called 4D design methodology, whereby the fourth dimension alludes to time and thus transformability. This means that any construction should be designed in order to face, during its life time, a necessary number of transformation scenarios. The Vrije Universiteit Brussel's group invested its major research efforts at the level of the design of the structural components (beams, plates, joints, etc.), in order to make them easily mounted, dismantled, re-usable: this is, among other successful techniques related to the building materials (C2C or 'cradle to cradle') and to the totality of the construction, shown in Fig. 8, where an additional bifurcation point is introduced, allowing for re-use of components. This is also called design by deconstruction. 


\section{CONCLUSIONS}

The indicator of volume, basis of the theory of MI, is a very efficient tool for comparing the necessary volume of fully stressed structures at conceptual design stage with a limited number of design variables. Though, except for resistance-related criteria, structures should also meet stiffness-related constraints (acceptable static displacements, global stability and absence of resonance, etc.) If one of these is not met, fully stressed design does not necessarily guarantee a light solution and one has to deal with a so-called design for stiffness problem. Different optimisation techniques should then be used, often at a higher computational cost. In this context, it is worth mentioning the work of Verbeeck et al. [47-49], who combined for the first time the advantages of $M I$, i.e. a reduced number of variables, with the accuracy of numerical optimisation techniques.

In fact, the indicator of volume bases its user-friendly characteristic on the exploration of only two of the three optimisation branches (we consider here only morphology optimisation, material optimisation can also result in significant volume gains but lies outside the scope of this study):

- sizing: to fix the cross-sectional dimensions or sizes of every element

- shape optimisation: to determine the global geometric layout of a structure

- topological optimisation: to select the pattern of connection of members and the number of elements in a structure

The use of the indicator of volume considers implicitly fully stressed design as being the optimal sizing and therefore does not further explore the first branch. The optimisation process is carried out on the a priori chosen shape and topology. In cases where only strength and element buckling are the dimensioning design criteria, this is a correct working method. When one of the stiffness constraints is not met, this assumption is no longer valid and sizing should be included in the optimisation process.

To compare with ease as much structural concepts as possible without need for detailed calculation, it is thus of prime importance to be able to distinguish design for strength problems from design for stiffness ones. The additional MI allow this distinction at conceptual design stage by using design graphics. Hence, these more recently developed tools provide a more consistent and general line in the application of $M I$. Their appropriate use is summarised in Fig. 7.

The combination of structural optimisation and the 4D design strategy also offers a double benefit! Considering the fact that the volume of the structural components is minimised, the initial material cost will drop. In addition the construction, maintenance and demolition cost will be minimal since the principle of reusing, easily assembling and dismantling is incorporated into the design. The result is highly interesting: a minimisation of the construction cost and the construction energy over the whole life cycle of the artefact and its components. Although this study had been done for transitory dwellings, this design philosophy can be extrapolated to other constructions as well (Fig. 8). The thesis of Paduart [50] convincingly proved this latter statement: it applies the 4D design methodology to the 'case study' of the post-war ('fifties') stock of social housing blocks in Belgium and underlines the added value of the combination of 4D design and optimisation techniques. Additionally, it addresses issues of building physics (acoustics, hygrothermal comfort, etc.), which are evaluated with similar instruments (LCC, LCA). 


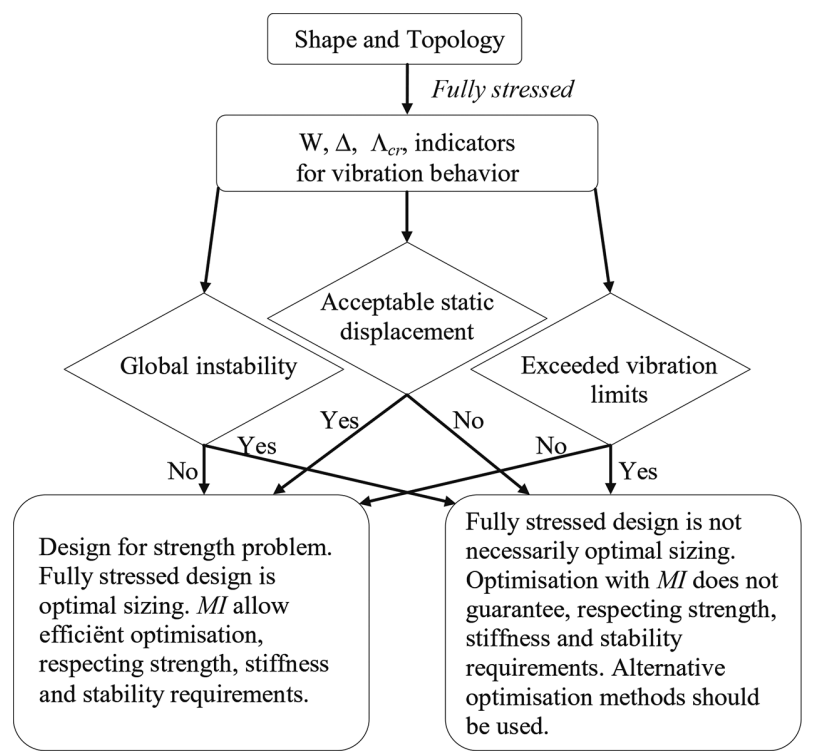

Figure 7: Flowchart for the use of morphological indicators at conceptual design stage [2].

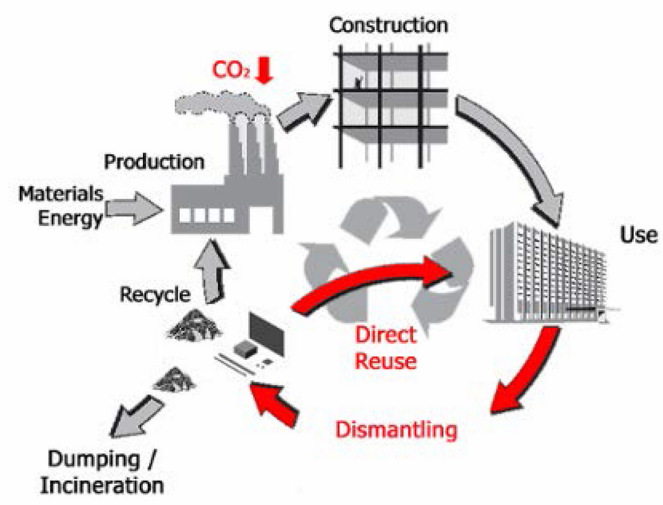

Figure 8: Proposed life-cycle model of a construction.

\section{REFERENCES}

[1] Samyn, P., Etude comparée du volume et du déplacement de structures isostatiques bidimensionnelles sous charges verticales entre deux appuis. Vers un outil d'évaluation et de prédimensionnement des structures (4 Tomes). PhD Thesis, Université de Liège, Liège, Belgium, 1999.

[2] Vandenbergh, T., Benchmarking optimisation at conceptual design stage with morphological indicators', PhD Thesis, Vrije Universiteit Brussel, Brussels, 2010.

[3] Debacker, W., Henrotay, C., De Wilde, W.P. \& Hendrickx, H., The HendrickxVanwalleghem design strategy. High Performance Structures and Materials III, UK WIT Press: Ashurst, 2006. 
[4] Debacker, W., Structural design and environmental load assessment of multi-use construction kits for temporary applications based on 4-dimensional design. PhD Thesis, Brussels University Press, Brussels, Belgium, 2009.

[5] French, M. J., Conceptual Design for Engineers. 2nd edn., The Design Council: London, 2006.

[6] Samyn, P., Etude de la morphologie des structures à l'aide des indicateurs de volume et de déplacement (3ème série), Académie Royale de Belgique, Classe des Sciences: Belgium, 2004.

[7] Maxwell, C., Scientific Papers, Cambridge University Press: United Kingdom, 1890.

[8] Michell, A.G.M., The limit of economy of material in frame structures. Philosophical Magazine,8(47),pp.589-597,1904.doi:http://dx.doi.org/10.1080/14786440409463229

[9] Lévy, M., La statique graphique et ses applications aux constructions, GauthiersVillars: Paris, 1888.

[10] Zalewski, W., The Flow of Forces (Excerpt from Notes on Structural Behaviour for Architectural Students. Massachusetts Institute of Technology: United States of America, 1980.

[11] Zalewski, W. \& Kus, S., Shaping structures of least weight. Proceedings of International Conference on Lightweight Structures in Civil Engineering, Warsaw, Poland, 1995.

[12] Zalewski, W. \& Kus, S., Shaping structures of least weight. Proceedings of the International Association for Shells and Spatials Structures, Stuttgart, Germany, 1996.

[13] Ripoll, V.Q. Sobre el teorema de Maxwell y la optimizacion de arcos de cubierto. Informes de la Construccion, 40(400), pp. 57-70, 1989. doi: http://dx.doi.org/10.3989/ ic.1989.v40.i400.1529

[14] Ripoll, V.Q., Sobre las formas de minimo volumen de las celosias de seccion constante. Informes de la Construccion, 43(418), pp. 61-77, 1992 doi: http://dx.doi.org/10.3989/ ic.1992.v43.i418.1355

[15] Van Steirteghem J., A contribution to the optimisation of structures using morphological indicators: (in)stability and dynamics. PhD Thesis, Vrije Universiteit Brussel, Brussels, Belgium, 2006.

[16] Latteur, P., Optimisation et prédimensionement des arcs et des treillis sur base d'indicateurs morphologiques - application aux structures soumises en partie ou en totalité au flambement. PhD Thesis, Vrije Universiteit Brussel, Brussels, Belgium, 2000.

[17] Latteur, P., Samyn, P. \& De Wilde, W.P., A search for efficient trusses. Proceedings of the International Association for Shells and Spatials Strucutres: International Symposium Bridging Large Spans, From Antiquity to the Present, Istanbul, Turkey, 2000.

[18] Latteur P., Samyn P. \& De Wilde, W.P., Etude du poids et de la raideur des treillis Warren, Pratt et Howe : Optimisation, prédimensionnement et comparaison sur base d'indicateurs morphologiques. Revue Française de Génie Civil, 4(4), 2000. doi: http:// dx.doi.org/10.1080/12795119.2000.9692283

[19] Latteur, P., Samyn, P. \& De Wilde, W.P., Optimisation des arcs funiculaires paraboliques et en chaînette, Aide à la conception sur base d'indicateurs morphologiques. Revue Française de Genie Civil, 5(1), 2001. doi: http://dx.doi.org/10.3166/rfgc.5.89-116

[20] De Wilde, W.P., Ontwerp van Constructies, Lecture notes, VUB Press, Vrije Universiteit: Brussel, 2007.

[21] NBN ENV1993-1, Design of steel structures - Part 1-1: general rules and rules for buildings (Belgian application document). Belgisch Instituut voor Normalisatie, Belgium, 2002. 
[22] Vanpee, P., Studie van de invloed van discrete secties bij de optimalistie van 2-dimensionale vakwerken, gebruikmakend van morfologische indicatoren. Master Eng. Sc. Thesis, Vrije Universiteit Brussel, Brussels, Belgium, 2007.

[23] Shanley, F.R., Weight-Strength Analysis of Aircraft Structures. 2nd edn. Dover Publications: New York, 1960.

[24] Cox, H.L., The Design of Structures of Least Weight, Pergamon; London, 1965.

[25] Van Steirteghem, J., De Wilde, W.P., Samyn, P., Verbeeck, B. \& Wattel, F., Optimum design of stayed columns with split-up cross arms. Adavances in Engineering Software, 36(9), pp. 614-625, 2005. doi: http://dx.doi.org/10.1016/j.advengsoft.2005.03.007

[26] Vandenbergh, T., De Wilde, W.P., Latteur, P., Verbeeck, B., Ponsaert, W. \& Van Steirteghem, J., Influence of stiffness constraints on optimal design of trusses using morphological indicators. Proceedings of the Third International Conference on High Performance Structures and Materials, eds C.A. Brebbia and W.P. De Wilde,. Ostend: Belgium, 2006.

[27] Vandenbergh, T., Van Steirteghem, J., De Wilde, W.P. \& Samyn, Ph., Dynamical analysis of the cable stayed beam, Proceedings of the International Association for Shells and Spatials Strucutres Conference on New Olympics, New Shells and Spatial Structures, Beijing, China, 2006.

[28] Vandenbergh, T., De Wilde, W.P., Latteur, P. \& Vantomme, L., Optimisation of statically determinate trusses considering planar instabilities at conceptual design stage. Proceedings for the Third International Congress dedicated to the art, science and practice of structural engineering (Structural Engineering World Congress), Bangalore, India, 2007.

[29] Vantomme, L., Uitbreiding van de theorie van de morfologische indicatoren naar het specifieke geval van de parabolische vakwerkboog: ontwerprichtlijnen en-strategie. Master Thesis, Vrije Universiteit Brussel, Brussels, Belgium, 2007.

[30] Vandenbergh, T. \& De Wilde, W.P., Optimisation at conceptual design stage with morphological indicators: pros and cons. Proceedings of NCTAM 2009, 8th National Congress on Theoretical and Applied Mechanics, Brussels, Belgium, 2009.

[31] Beards, C.F., Structural Vibrations: Analysis and Damping. Arnold: London, 1996.

[32] Vandenbergh, T. \& De Wilde, W.P., Vibration behavior of trusses at conceptual design stage, under pedestrian loading and using morphological indicators. Proceedings of the Second ECCOMAS Thematic Conference on Computational Methods in Structural Dynamics and Earthquake Engineering, eds. M/ Papadrakakis, N.D. Lagaros \& M. Fragiadakis. Rhodos, Greece, 2009.

[33] Vandenbergh, T. \& De Wilde, W.P., Vibration behavior of statically determinate arches, under pedestrian loading and using morphological indicators. Proceedings of the International Association for Shells and Spatials Strucutres Conference on Evolution and Trends in Design, Analysis and Construction of Shell and Spatial Structures, eds. A. Domingo \& C. Lazaro, Valencia, Spain, 2009.

[34] Vandenbergh, T., De Wilde, W.P. \& Latteur, P., Basis for dynamic analysis and optimisation of statically determined 2D (un)damped structures at conceptual design stage using morphological indicators. Proceedings of the 17th International Association for Bridge and Structural Engineering Congress on Creating and Renewing Urban Structures - Tall Buildings, Bridges and Infrastructure, Chicago, USA, 2008. 
[35] British Standard 5400, Steel, Concrete and Composite Bridges - Part 2: Specifications for Loads: Appendix C: Vibration Serviceability Requirements for Foot and Cycle Track Bridges, British Standards Association: London, 1978.

[36] Bro2004, Väverkets allmänna tekniska beskrivning för nybyggande och förbättring av broar, Svesnk Byggtjänst: Sweden: 2004.

[37] Zivanovic, S., Pavic, A. \& Reynolds, P., Vibration serviceability of footbridges under human-induced excitation: a literature revue. Journal of Sound and Vibration, 279, pp. 1-74, 2005. doi: http://dx.doi.org/10.1016/j.jsv.2004.01.019

[38] Vandenbergh, T., Verbeeck, B. \& De Wilde, W.P., Dynamical analysis and optimisation of statically determinate trusses at conceptual design stage. Proceedings of the ECCOMAS Thematic Conference on Computational Methods in Structural Dynamics and Earthquake Engineering, eds. M. Papadrakakis, D.C. Charmpis, N.D. Lagaros, \& Y. Tsompanakis, Crete, Greece, 2007.

[39] Lefevre, A., Dynamica van geoptimalseerde vakwerkstructuren in voorontwerpstadium met Morfologische Indicatoren: Verticale Voetgangersexcitatie. Master Eng. Sc. Thesis, Vrije Universiteit Brussel, Brussels, Belgium, 2008.

[40] Spranghers, K., Optimalisatie van boogconstructies in conceptueel ontwerpstadium met morfologische indincatoren en rekening houdend met het trillingsgedrag van (on) gedempte systemen. Master Thesis, Vrije Universiteit Brussel, Brussels, Belgium, 2008.

[41] Vandenbergh, T., De Wilde, W.P. \& Latteur, P., Optimisation at conceptual design stage with morphological indicators: design for strength or design for stiffness? Proceedings of the Fourth International Conference on High Performance Structures and Materials, eds. W.P. De Wilde \& C.A. Brebbia, Algarve, Portugal, 2008.

[42] Vandenbergh, T., Dynamische analyse van de getuide balk. Master Thesis, Vrije Universiteit Brussel, Brussels, Belgium, 2005.

[43] Vandenbergh, M., Studie van het statisch en dynamisch gedrag van de enkelvoudige getuide balk mbv morfologische indicatoren. Master Thesis, Vrije Universiteit Brussel, Brussels, Belgium, 2007.

[44] Arup Vibration Seminar, Engineering for Structural Vibration - Current Developments in Research and Practice, Institution of Mechanical Engineers: London, 2001.

[45] Association Française de Génie Civil (Working group lead by Charles, P. and Hoorpah, P.). Assessment of Pedestrian-Induced Vibratory Behaviour of Footbridges, Association Française de Génie Civil (AFGC): France, 2006.

[46] Jodidio, P., Santiago Calatrava, Taschen, Köln, 2003, available at: www.taschen.com.

[47] Verbeeck, B., De Wilde, W.P., Samyn, P. \& Van Steirteghem, J., The use of genetic algorithms and morphological indicators in the optimisation of 2D trusses. Proceedings of the Second International Conference on High Performance Structures and Materials, eds. C.A. Brebbia \& W.P. De Wilde, Ancona, Italy, 2004.

[48] Verbeeck, B., Van Steirteghem, J., De Wilde, W.P. \& Samyn, P., The need of numerical techniques for the optimisation of structures with morphological indicators. Proceedings of the Ninth International Conference on Computer Aided Optimum Design in Engineering, eds. S. Hernandez \& C.A. Brebbia, Skiathos, Greece, 2005.

[49] Verbeeck, B., Van Steirteghem, J., De Wilde, W.P. \& Samyn, P., Combining different optimisation techniques for trusses subjected to unusual load cases. Proceedings of WCSM 6, Rio de Janeiro, Brazil, 2005.

[50] Paduart, A., Re-design for change. A 4 dimensional renovation approach towards a dynamic and sustainable building stock. PhD Thesis, MeMC Vrije Universiteit Brussel, Brussels, Belgium, 2012. 